\title{
The population dynamics of disease on short and long time-scales
}

Article

Accepted Version

Shaw, M. W. (2014) The population dynamics of disease on short and long time-scales. European Journal of Plant Pathology, 138 (3). pp. 487-497. ISSN 0929-1873 doi: https://doi.org/10.1007/s10658-013-0339-8 Available at https://centaur.reading.ac.uk/37041/

It is advisable to refer to the publisher's version if you intend to cite from the work. See Guidance on citing.

To link to this article DOI: http://dx.doi.org/10.1007/s10658-013-0339-8

Publisher: Springer

All outputs in CentAUR are protected by Intellectual Property Rights law, including copyright law. Copyright and IPR is retained by the creators or other copyright holders. Terms and conditions for use of this material are defined in the End User Agreement.

\section{$\underline{\text { www.reading.ac.uk/centaur }}$}

\section{CentAUR}

Central Archive at the University of Reading

Reading's research outputs online 
The population dynamics of disease on short and long time-scales

M. W. Shaw

School of Agriculture, Policy and Development, University of Reading,

Whiteknights, Reading, UK (e-mail: m.w.shaw@reading.ac.uk)

Keywords: co-evolution, metapopulation, population dynamics, spatial distribution 
Observational evidence concerning the distribution of plant pathogen population sizes or densities as a function of time-scale or spatial scale is scarce. For wild pathosystems we can only get indirect evidence from evolutionary patterns and the consequences of biological invasions. We have little or no evidence bearing on extermination of hosts by pathogens, or successful escape of a host from a pathogen. Evidence over the last couple of centuries from crops suggest that the abundance of particular pathogens in the spectrum affecting a given host can vary hugely on decadal time-scales. However, this may be an artefact of domestication and intensive cultivation.

Host-pathogen dynamics can be formulated mathematically fairly easily - for example as SIR-type differential equation or difference equation models, and this has been the (successful) focus of recent work in crops. "Long-term" is then discussed in terms of the time taken to relax from a perturbation to the asymptotic state. However, both host and pathogen dynamics are driven by environmental factors as well as their mutual interactions, and both host and pathogen co-evolve, and evolve in response to external factors. We have virtually no information about the importance and natural role of higher trophic levels (hyperpathogens) and competitors, but they could also induce long-scale fluctuations in the abundance of pathogens on particular hosts.

In wild pathosystems the host distribution cannot be modelled as either a uniform density or even a uniform distribution of fields (which could then be treated as individuals). Patterns of short-term density-dependence and the detail of host distribution are therefore critical to long-term dynamics. Host density distributions are not usually scale-free, but are rarely uniform or clearly structured on a single scale. In a (multiply structured) metapopulation with co-evolution and external disturbances it could well be the case that the time required to attain an equilibrium (if it exists) based on conditions stable over that timescale is longer than that time-scale. Alternatively, local equilibria may be reached fairly rapidly but the meta-population equilibrium be very slow; there is plausible support for this in some genomic parasites. In either case, meta-stability on various time-scales is a more relevant than equilibrium concepts in explaining observed patterns. 


\section{INTRODUCTION}

In the mid- $19^{\text {th }}$ century the major problem in UK wheat-growing was black stem rust caused by Puccinia graminis (Shaw, 2011). This was normal for farmers, and had perhaps been for thousands of years - the existence of the roman god of rust, Robigus, shows that rust was a serious problem in classical times. If nineteenth century farmers had known what it was, they would have noticed that septoria tritici blotch caused by Zymoseptoria tritici (=Mycosphaerella graminicola) was common (Bearchell et al., 2005). In the 1970s, leaf blotch caused by Phaeosphaeria nodorum and powdery mildew were the concerns (King, 1977). Now - but perhaps not for much longer with the spread of Ug99 derived genotypes of the pathogen - black stem rust is effectively absent for UK farmers and all efforts concentrate on Z. tritici (Paveley et al., 2013). In the same way, we see a sequence of invasions of wild ecosystems, most publicly in forests: chestnut blight in north America in the late $19^{\text {th }}$ century, oak powdery mildew in Europe at the start of the $20^{\text {th }}$ century (Mougou et al., 2008), two waves of dutch elm disease in the mid $20^{\text {th }}$ century (Brasier \& Buck, 2001), ramorum blight of tanoak (Meentemeyer et al., 2008), larch (Brasier \& Webber, 2010) and other species in the last 20 years, and so on. Evidently, at present, the abundance of different pathogens is quite variable on a time-scale of centuries. Most textbooks, however, will list diseases and their importance as a static phenomenon, unqualified by phrases such as "at the time of writing". Pathologists, probably inevitably, mostly understand what we learnt and saw while we trained as a standing state of affairs, rather than an instant in a constantly shifting scene.

In each individual case above, an explanation can be given for the changing prevalence patterns, and the invasions cited are clearly human mediated. But is this situation normal in the life of a plant (or pathogen species), in the sense of having shaped, over evolutionary time, the phenotypes we see? Disease in unmanaged settings does not usually seem severe: typical levels are relatively low, though many examples - which are likely to be those chosen for study - show strong effects on host populations and therefore on communities (Augspurger, 1983; Bull et al., 2012; Packer \& Clay, 2004; 
Roy et al., 2011; Zadoks, 1987). This is most strikingly the case where classical biocontrol has been effective (Tomley \& Evans, 2004). Where effects are sufficiently severe, they will leave no evidence, since the host will be extinct. So one goal of plant or plant pathogen population biology might be to clarify what to expect as plant disease problems in the world as human settlement becomes complete. It seems inevitable that the world will become divided into land intensively managed for food, fuel and fibre and a smaller proportion of land intended to provide the broad sweep of ecosystem services. Two general questions arise. First, what will be a long-term sustainable strategy for managing these two components? Second, how frequently will new pathogen problems arise in each component, and what form and impact will they have?

\section{Process description}

These questions are at least in part about population dynamic processes and their rates. We need to know how pathogen incidence (i.e. the presence or absence of the pathogen in a small region of space during short time intervals), or the incidence of pathogen-induced mortality, vary on a range of spatial and temporal scales (Fig. 1). This range of scales, of course, is continuous; we can choose a set of scales to examine that correspond to particular processes governing our observations: infection, death, genetic change, genetic re-design, climate change, tectonic change. Then we can phrase questions about how plant pathosystems work at the whole range of scales. Two metapopulations with different spatial structures will not be equivalent. Their structure itself will change over time and their current state will often depend on how that structure arose, rather than depending only on the current structure. If there is structuring on multiple or all scales (Fig 2), this needs to be allowed for in some way in dynamical models.

Natural time-scales - the time taken for a pathosystem to recover to a long-term state after a perturbation of some kind -are set by the twin dynamics of infected units of host and infectious units of pathogen. The scales appropriate for study of different phenomena may differ. For example, the time-scales appropriate for studying Z. tritici on its host, wheat, differ greatly according to the 
question we are asking. Within a season, temperature effects can be partially compensated for by using thermal time to obtain a single number. A wheat leaf lives roughly $500^{\circ} \mathrm{C}$-day (Weir et al., 1984 ) and Z. tritici has a generation time of roughly $300{ }^{\circ} \mathrm{C}$-day (roughly, because response is not actually linear with temperature: Lovell et al. (2004)). So the natural timescale of pathogen response within a season is of the order of $500^{\circ} \mathrm{C}$-day, or $25 \mathrm{~d}$ at $20^{\circ} \mathrm{C}$. Within this time there is complete turnover of infected units. Although sexually reproducing $Z$. tritici persists much longer than this, the dynamics are largely set by the faster process (Eriksen et al., 2001). But the host wheat plants (as opposed to leaves) reproduce annually, and this time-scale is appropriate for considering the effects of disease on the population. The difference becomes dramatic with trees, or where there is a longlived seed-bank as with Brassica rapa.

Depending on dispersal method (for example, soil-borne mycelium or resting spores; aerially dispersed short-lived spores; vectored transmission) we can consider pathogens as foraging in either time or space for new hosts. Foliar pathogens commonly forage in space, with relatively short-lived propagules capable of moving to new hosts in a different location. Soil-borne pathogens frequently have propagules adapted to survive long periods in the soil, essentially waiting for the recurrence of a host close by. Evolutionary trade-offs are likely to occur between these modes of foraging and the balance of long-distance and short-distance spatial movement, depending on the pattern of occurrence of susceptible hosts in both space and time. For example, in a fungus like Botrytis cinerea allocation of more resource to sclerotia (foraging in time) would be expected to reduce the resource available for conidia (foraging in space via aerial dispersal). Foraging for hosts in space or in time can both be formulated mathematically fairly easily - for example as SIR-type differential equation or difference equation models - and this has been the (successful) focus of recent work in crops. "Long-term" is then discussed in terms of the asymptotic behaviour of the model. However, both host and pathogen dynamics are driven by environmental factors as well as their mutual interactions, and both host and pathogen co-evolve, and evolve in response to external factors. We 
cannot hope to have a detailed understanding of all these processes, but the choice of what to ignore should not be arbitrary.

Predictive understanding of the effect of changing patterns of vegetation management or type requires that the factors capable of producing large changes have been identified. Since large and long-term changes in disease prevalence occur unexpectedly (Bearchell et al., 2005; Walters et al., 2008), it seems we do not understand important components of many pathosystems. In crops, changes often, but not always, appear attributable to changes in the host-pathogen relationship. Parasites and predators frequently influence the population levels of animal pests (Gagic et al., 2011). Both competitors and hyperparasites are commonly found in natural pathosystems, and commercial biocontrol products based on some of these are available. We have virtually no information about the importance in natural fungal and bacterial plant pathogen population dynamics of competition and organisms at higher trophic levels. They could, however, induce important long-scale fluctuations in the abundance of pathogens on particular hosts (Brasier, 1990; Shaw, 2013).

If the available data are relatively short-term it is usual to assume that we are observing a situation that is typical, in the sense of being a common state in the unknown long run distribution. We are therefore interested in "typical" model predictions for comparison (cf. Jeger et al, this volume). To obtain these, the first focus in analysing a model is often to derive long-run or asymptoptic behaviour. (This does not apply to the kinds of models used in practical agriculture to forecast disease, which are concerned with arbitrary starting conditions, and with dynamic responses to environmental conditions, handled in what is often a rather ad hoc manner). In many dynamical models, the long-run behaviour involves a realisable equilibrium (though it need not be locally stable), and it is tempting to regard "typical" observations as arising from perturbations around that equilibrium. However, if the time-scale of perturbation is short compared with the equilibration time-scale, the "typical" state may be far from the equilibrium. There is then a problem in inferring 
from field observations what the underlying ecological forces are, and in making reliable predictions about how the system will evolve forward in time.

For example, the standard starting point for most modelling currently involves an SIR model or a modification of an SIR model, with a focus on $\mathrm{R}_{0}$ either at very low density (invasibility into naive host populations and persistence) or at equilibrium (for example, to look at coexistence of genotypes of pathogen) (e.g. Cunniffe \& Gilligan, 2010; Madden et al., 2007; Scherm et al., 2006). For foliar pathogens in such a framework, the life-time of an uninfected leaf sets a natural turn-over time (as above), and an "equilibrium" is often derived and analysed on this kind of time-scale. But in plant modules which turn over annually (for example, leaves on trees, annual plants) equilibrium cannot be reached within a season, so the effect of the off-season on a model equilibrium may be dramatic. Essentially, the underlying equations are perturbed so greatly and so frequently that the short-term description gives no guide to medium term behaviour. In longer-lived plant modules, such as the root-systems of perennial herbs, or the wood structure of trees, natural time-scales may be much longer - possibly centuries in forests (Field et al., 2012) - and the question then becomes how equilibrium-based understanding can be used in the face of evolutionary, climatic and community change.

\section{Possible patterns}

Patterns of interest in long run dynamics without external perturbation include the simplest: a stable equilibrium on the timescale of either the host population or annual seasonality. There can also be various kinds of recurring pattern, with regular or fairly regular recurrence (from periodicity to chaos). A "toy" (simplified) model of interactions with other trophic levels shows that very simple dynamics could give disease severity patterns which would appear to be uncaused sporadic outbreaks (Fig. 3) (Shaw, 2013) . (Whether more realistic models with random disturbances and variations in parameters would give simpler or more complex behaviour is not known. The 
behaviour of a particular model intended to represent a mycovirus-pathogen interaction was relatively insensitive to such disturbances (Shaw, 1994).)

It could be the case that generalisations or predictions are not possible because stochastic disturbances occur more frequently than the establishment of regular patterns. The latter is clearly true at present, as movement of hosts in trade and as stowaways on passenger transport is rapidly introducing all pathogens to all hosts in a gigantic global selection experiment (Newcombe \& Dugan, 2010)(so that our era has been termed the "homogocene"). However, substantial vegetational change driven by climate has occurred throughout the Holocene (Fig. 4), so that a stable disease association might be seen as lasting at most a few thousand years, or no more than a few tens of generations of trees in stable forest.

In establishing or re-invading forest, of course, the effective generation time may be only decades and selection will be very rapid. In trees in the mature forest case, there will be two time-scales to consider, one for foliar pathogens, and another for pathogens of the standing structure of the trees. For foliar pathogens, a dynamical equilibrium is certainly appropriate, but an evolutionary equilibrium would be surprising except for the most devastating diseases, because the host evolutionary time-scale is so much longer than the time required for the pathogen to reach its dynamical equilibrium. This implies that a tree host population will usually lag behind a foliar pathogen in an R-avR mediated co-evolutionary race. The result might be: (possibly local) extinction of tree species; reduction to lower population density; or greater investment in generalised structural and biochemical defences which are harder for a pathogen to overcome, but possibly a greater metabolic expense. For pathogens of the woody structure on the other hand, there may not be time for an equilibrium between host and pathogen to develop before the forest moves due to climatic shifts. Where a short-lived plant is dependent on gaps or other erratic processes to reproduce, the effective generation time may be much longer than the time during which the plant is apparent (that is, roughly speaking, susceptible and available for infection:(Begon et al., 1996)) to its 
pathogens. Under some circumstances, interactions with higher trophic levels might produce very long-term alterations in intensity (Evans, 2008). Even where there is time for a population dynamical asymptote to be reached, there may not be time for co-evolutionary processes to reach their asymptotic state.

Now consider a population structure with several distinct levels. Within a unit at each level, there is a process of infection and loss which could be described by a chain of infected sub-units over time, and will have a dynamical behaviour emerging from both the instantaneous driving forces acting and the variation available in both host and pathogen. If the lifetime of such a pathogen infection chain is finite on a small spatial scale, then indefinite persistence at the next scale up is determined by the process of infection and loss at that largerscale. This will be on a longer time-scale, potentially much longer; it is reasonable to assume that the variance of the time during which disease persists at the larger scale will also be greater. This means that if we observe a large number of such weakly linked pathosystems at a single time, we will see hosts with many diseases and hosts with few, in ways related to the spatial structure of the species as a whole.

In some spatial population structures $R_{0}$ may be large on small scales, in localised host clumps, but small on larger scales because of the accidents of the host distribution. In this setting, pathogens could emerge locally and reduce or eliminate the local population, but eventually die out. Long-term persistence will depend on the population process describing birth and death of infected host populations on the large scale, not on the scale of the individual plant. Loss of the pathogen from the system would be observationally indistinguishable in the surviving hosts from absence of disease, although traces might be left in the genome if one knew where to look. However, comparison of model predictions with observations requires careful consideration of the processes operating at different time-scales. 
The concepts may be clarified by quoting an example from outside plant pathology, but which has rather similar dynamics. The grasshopper Eyprepocnemis plorans lives in a metapopulation of transient habitats in Iberia. Some populations contain a genomic parasite - B chromosome - which is damaging to an individual if several copies are present. However, in naive populations, the chromosome is passed on to many more of the offspring than the Mendelian expectation, and so tends to increase rapidly. This favours suppressor mutations, which increase in frequency rapidly and lower the transmission rate towards the Mendelian expectation. There is a close dynamical analogy with a pathogen which spreads rapidly in a naïve population, but against which polygenic resistance accumulates. Selection against individuals with many B chromosomes rapidly reduces the average B-frequency and therefore the strength of selection; in the analogous plant disease situation, selection against susceptible hosts will reduce the rate of increase and average severity of the disease, and therefore the strength of selection for resistance. In diploid organisms, recessive genetic variance for susceptibility will also be increasingly masked by dominant alleles, also slowing the rate of selection. Depending on the extent of variation in virulence available in the pathogen (Burdon \& Thrall, 2009) - allowing selection for increased transmission (virulence) - elimination of the B (三pathogen) will be many times slower than the initial increase because as the B (disease) becomes rarer the strength of selection for resistance decreases. This allows a long time for the very rare events in which an individual with a B (equivalently, a pathogen propagule) travels to a new population and infect it. The result is a deep time dynamic in which the B is eliminated completely, but a long-term state in which the "typical" observation is of a population with a moderate frequency of a marginally harmful element with a transmission rate which would not allow invasion of the population in which it exists (Camacho et al., 1997).

In such a multi-scale picture of a plant pathosystem the pathogen must persist across scales if it is able to persist indefinitely. At the largest time-scale, a host-pathogen association must start with an organism - perhaps a pathogen of another plant, perhaps a commensual - acquiring an ability to attack a new host. If the effect of the pathogen is to cause severe disease, the host density will fall. 
In some cases the effect will initially be to alter the age distribution, either by killing larger older individuals and favouring smaller or younger, or by killing younger individuals. In a mixed species community, either will usually result in lower density over time. This could cause extinction (locally or globally) of both host and pathogen. Paradoxically, this could be quite common, since the extinction will not necessarily leave any evidence we can now detect.

The larger question arising is how frequent different scenarios - origination of a disease, extinction of host or of pathogen, metastable equilibria - are. A handbook of wheat diseases will cover many tens of pathogens, but in one area and at one time few will be of concern to most growers. (In the UK, for example, growers will be worried about take-all, eyespot, leaf and stripe rust, $Z$. tritici and Fusarium ear blights (Paveley et al., 2013)). So is the "normal" situation one in which most diseases are close to an equilibrium with their hosts on a decadal time-scale, with low observed impact? Is this because climate, the pattern of host distribution, or the transient effects of past disease has reduced the pathogen population density to a low equilibrium? Or does the observed distribution reflect a large-scale birth-death process in which the units are whole species?

\section{Observations}

It is clear from both phylogenetics and fossil evidence that major taxa of fungal plant pathogens have co-existed with land plants since their evolutionary emergence, and - since disease can be limiting in marine macro-algae (Bull et al., 2012) - presumably before. The fact that any fossil evidence of microbial colonisation of plants by multiple taxa can be found (Berbee \& Taylor, 2007; Currah \& Stockey, 1991; Dieguez \& Lopez-Gomez, 2005) implies that disease has been widespread at all times since themovement of macroscopic life onto land. Pathogens occur within multiple lineages of ascomycetes (James et al., 2006) at many depths within the phylogenetic tree. This suggests that new pathogenic forms could still be emerging, especially where pathogenicity might be incidental to a mutualism. Thus on a time-scale of hundreds of millions of years, the position is reasonably clear. 
However, the jump is large to the decadal time-scale on which most information about variation in population size or new invasion has been obtained..

Observational evidence concerning the distribution of plant pathogen population sizes or densities as a function of time-scale between the extremes is thin even for crop pathogens, as discussed below. For wild pathosystems we can only get indirect evidence from evolutionary patterns (Burdon \& Thrall, 1999) and the consequences of biological invasions. We have little or no evidence bearing on extermination of hosts by pathogens, or successful escape of a host from a pathogen, since these events leave only faint, if any, traces. However, evidence over the last couple of centuries in crops suggests that the abundance of particular pathogens in the spectrum affecting a given host can vary hugely on decadal time-scales and that birth of new pathogenic associations is disconcertingly frequent, as discussed below. This may be an artefact of domestication and intensive cultivation (Stukenbrock \& McDonald, 2008); understanding in a wider range of pathosystems would be very desirable.

In crops, it is more difficult to understand variation in pathogen severity and incidence because coevolution is accelerated and unbalanced by conscious breeding, and the area and density of available host is rather insensitive to pathogen population density. Extraordinary advances have been made using molecular evidence, but these have so far only partly answered the question of the long-term influence of pathogens on their hosts and the communities containing them. By the nature of the evidence, such studies tend to say "something happened", rather than "this happened". The recently published details of $P$. infestans, Rhynchosporium spp. and Pyrenophora tritici-repentis all show recent evolution of the current pathogen-host associations: Rhynchosporium commune separated from congeners between 1200 and 3600 years ago (Zaffarano et al., 2008); P. infestans split from $P$. mirabilis between about 850-1800 years ago (Kentaro Yoshida et al., 2013); and $P$. tritici-repentis acquired its pathogenicity cassette in the mid-20 $0^{\text {th }}$ century (Friesen et al., 2006). However, similar records are sparse for complexes involving neither the artificially enhanced host 
densities of crops, nor novel geographic invasions. We therefore cannot yet say whether or not emergence of a new pathogen into a host is a frequent occurrence on time-scales of millions of years, comparable with speciation in higher plants. Also, we have very few continuous and long-lived records of disease incidence or severity on any scale, so we can say little about the proportion of host populations in which disease routinely regulates or affects population size, and therefore affects long-term evolutionary and ecological patterns.

For Phytophthora infestans, we have historical records of the more spectacular consequences of the invasion of the pathogen across the range of the host, but, despite this, currently no easily available continuous record of severity, date of onset of the epidemic or similar measurements, largely because historical records are unquantifiable (Fig. 5). We cannot saymuch more than that the disease has continued to be a problem, despite breeding, in most areas where potato is grown. For the two septoria blotches of wheat, caused by Zymoseptoria tritici (= Septoria tritici = Mycosphaerella graminicola) and Phaeosphaeria nodorum, we have a 160-year record of abundance from the longterm Broadbalk wheat experiment at Rothamsted in England. This shows a complete cycle of change over the period: $Z$. tritici DNA was ten times as abundant as $P$. nodorum in the mid $19^{\text {th }}$ century, declining to less than a thousandth as abundant in the 1970s before recovering to the mid $19^{\text {th }}$ century position now (Bearchell et al., 2005). In this case we have clues to the cause. It is unrelated to climate - wet weather favours both fungi (Shaw et al., 2008) - and there is no evidence for shorter-term cycles, chaos, etc. However, the change is very closely correlated with national oxidised sulphur emissions, and there is some evidence that the sulphate nutrition of wheat can alter the balance between the two fungi (Chandramohan \& Shaw, 2013), though other factors must also be involved. If similar nutrient-based phenomena affecting host resistance but not other aspects of phenotype are common, there would be an added stochastic factor contributing to disease patterns in natural communities, reducing the influence of pure population dynamic factors. The information in this particular series was quite unexpected but, because it concerns wheat, not very informative about what we should expect in a typical wild community. 
Rust, smut and other fungal spores can be found in pollen cores (e.g. Innes et al., 2006) , but do not give evidence either as to host nor to the abundance of disease and can often only be identified to a taxonomic level much higher than species. Although DNA has been successfully amplified from individual pollen grains 10000 years old (Bennett \& Parducci, 2006), there are no studies published on pathogen spores. It would fascinating to see long-term series of spore abundance of particular pathogens reconstructed, especially if host pollen records were also available; however, it will not be easy and could only be done for anomalously favourable host-pathogen associations.

Long-term data-sets describing pathogen abundance will remain scarce. An alternative is to look for cross-sectional data on many species, asking about their general state. However, most studies have focussed on particular pathosystems. This can make it hard to find generalisations applying to communities in general because we are biased to the easily visible and frequent pathogens (and hosts). In studies of grassland regenerating after cultivation from the seedbank and surrounding vegetation Peters (1994) found a few percent of leaf area of many of the species present to be diseased; this appeared relatively stable during the summer of the three years sampled (Shaw \& Peters, 1994). For most species, the natural turn-over of leaves was rapid in relation to the build-up of pathogen and limited severity; this may be an evolved response (van den Berg \& van den Bosch, 2004; van den Berg et al., 2008). Rust (Puccinia coronata) on the dominant grass species (Holcus lanatus) reduced its dominance slightly and increased diversity in the community(Peters \& Shaw, 1996). H. lanatus stood out in these data as having high rust severity, and is usually one of the easiest common UK grasses in which to find rust. This, of course, makes the association easy to study and possibly untypical. An unavoidable focus on systems in which disease is easy to see and reasonably abundant leads to a strongly biassed choice of model systems. For example, Microbotryum on Silene (Bernasconi et al., 2009; Carlsson-Graner \& Thrall, 2002) is an attractive system to study, in part because it is fairly easy to find infected individuals. By contrast, the rare Puccinia longissima on Koeleria cristata (Ellis \& Ellis, 1997) would be an unwise choice of experimental system and unlikely to attract funding, since it is hard to do experiments if most of the 
effort has to go into finding examples of the interaction; yet this could be at least as representative a study as a more tractable model system, especially since it would be more likely to shed light on how an obligate pathogen can persist, yet usually be rare.

\section{Conclusions}

The purpose of this paper is to draw attention to the topic as an interesting one for discussion. The conclusion is less a conclusion about how the wold is than a group of hypotheses:

- new pathogenic threats arise frequently;

- plant defences mostly reduce pathogenic disease to levels unimportant in host population dynamics;

- diseases that act as regulatory agents on a community are transient and relatively rare phenomena;

- co-evolution leads to dynamics which mean that surviving lineages of plant pathogens undergo frequent host-shifts (within or between host species) ;

- we will find most systems in transient states that can only be understood by considering metastable states of wider communities.

My contention is that trying to prove these hypotheses wrong will greatly improve our understanding of the place of plant pathogens in plant ecology. 


\section{References}

Anon (1890) The potato blight in Ireland: a plain statement of facts collected from various independent authorities. The Irish Loyal and Patriotic Union, Dublin and London.

Augspurger, C. (1983) Seed dispersal of the tropical tree Platypodium elegans and the escape of its seedlings from fungal pathogens. Journal of Ecology, 71, 759-771.

Bearchell, S.J., Fraaije, B.A., Shaw, M.W., \& Fitt, B.D.L. (2005) Wheat archive links long-term fungal pathogen population dynamics to air pollution. Proceedings of the National Academy of Sciences of the USA, 102, 5438-5442.

Begon, M., Mortimer, M., \& Thompson, D.J. (1996) Population Ecology: a unified study of animals and plants, 3rd edn. Blackwell, Oxford.

Bennett, K.D. \& Parducci, L. (2006) DNA from pollen: principles and potential. The Holocene, 16, 1031-1034.

Berbee, M.L. \& Taylor, J.W. (2007) Rhynie chert: a window into a lost world of complex plant-fungus interactions. New Phytologist, 174, 475-479.

Bernasconi, G., Antonovics, J., Biere, A., Charlesworth, D., Delph, L.F., Filatov, D., Giraud, T., Hood, M.E., Marais, G.A.B., McCauley, D., et al. (2009) Silene as a model system in ecology and evolution. Heredity, 103, 5-14.

Brasier, C.M. (1990). The unexpected element: mycovirus involvement in the outcome of two recent pandemics, Dutch elm disease and chestnut blight. (In J.J. Burdon \& S.R. Leather(eds), Pests, Pathogens and Plant Communities, (pp. 289-307). Oxford: Blackwell.)

Brasier, C.M. \& Buck, K.W. (2001) Rapid evolutionary changes in a globally invading fungal pathogen (Dutch elm disease). Biological Invasions, 3, 223-233. 
Brasier, C.M. \& Webber, J.F. (2010) Sudden Larch death. Nature, 466, 824-825.

Bull, J.C., Kenyon, E.J., \& Cook, K.J. (2012) Wasting disease regulates long-term population dynamics in a threatened seagrass. Oecologia, 169, 135-142.

Burdon, J.J. \& Thrall, P.H. (1999) Spatial and temporal patterns in coevolving plant and pathogen associations. American Naturalist, 153 Supplement, S15-33.

Burdon, J.J. \& Thrall, P.H. (2009) Coevolution of plants and their pathogens in natural habitats. Science, 324, 755-756.

Camacho, J.P.M., Shaw, M.W., López-León, M.D., Pardo, M.C., \& Cabrero, J. (1997) Population dynamics of a selfish B chromosome neutralized by the standard genome in the grasshopper Eyprepocnemis plorans. American Naturalist, 149, 1030-1050.

Carlsson-Graner, U. \& Thrall, P.H. (2002) The spatial distribution of plant populations, disease dynamics and evolution of resistance. Oikos, 97, 97-110.

Chandramohan, P. \& Shaw, M.W. (2013) Sulphate and sulphurous acid alter the relative susceptibility of wheat to Phaeosphaeria nodorum and Mycosphaerella graminicola Plant Pathology, in press.

Cunniffe, N.J. \& Gilligan, C.A. (2010) Invasion, persistence and control in epidemic models for plant pathogens: the effect of host demography. Journal of the Royal Society Interface, 7, 439-451.

Currah, R.S. \& Stockey, R.A. (1991) A fossil smut fungus from the anthers of an Eocene angiosperm. Nature, 350, 698-699.

Dieguez, C. \& Lopez-Gomez, J. (2005) Fungus-plant interaction in a Thuringian (Late permian) Dadoxylon sp in the SE Iberian Ranges, eastern Spain. Palaeogeography Palaeoclimatology Palaeoecology, 229, 69-82. 
Ellis, M.B. \& Ellis, J.P. (1997) Microfungi on land plants: an identification handbook, New enlarged edn. Richmond Publishing, Slough, UK.

Eriksen, L., Shaw, M.W., \& Østergård, H. (2001) A model of the effect of pseudothecia on genetic recombination and epidemic development in populations of Mycosphaerella graminicola.

Phytopathology, 91, 240-248.

Evans, H.C. (2008) The endophyte-enemy release hypothesis: implications for classical biological control and plant invasions. In XII International Symposium on Biological Control of Weeds, pp. 20-25, La Grande Motte, France.

Field, S.G., Schoettle, A.W., Klutsch, J.G., Tavener, S.J., \& Antolin, M.F. (2012) Demographic projection of high-elevation white pines infected with white pine blister rust: a nonlinear disease model. Ecological Applications, 22, 166-183.

Friesen, T.L., Stukenbrock, E.H., Liu, Z.H., Meinhardt, S., Ling, H., Faris, J.D., Rasmussen, J.B., Solomon, P.S., McDonald, B.A., \& Oliver, R.P. (2006) Emergence of a new disease as a result of interspecific virulence gene transfer. Nature Genetics, 38, 953-956.

Gagic, V., Tscharntke, T., Dormann, C.F., Gruber, B., Wilstermann, A., \& Thies, C. (2011) Food web structure and biocontrol in a four-trophic level system across a landscape complexity gradient. Proceedings of the Royal Society B: Biological Sciences, 278, 2946-2953.

Innes, J., Blackford, J., \& Chambers, F. (2006) Kretzschmaria deusta and the northwest European midHolocene Ulmus decline at Moel y Gerddi, north Wales, United Kingdom. Palynology, 30, 121-132.

Jalas, J. \& Suominen, J., eds. (1986) Atlas florae europaeae: distribution of vascular plants in Europe. Vol. 7 Caryophyllaceae (Silenoideae). 
James, T.Y., Kauff, F., Schoch, C.L., Matheny, P.B., Hofstetter, V., Cox, C.J., Celio, G., Gueidan, C., Fraker, E., Miadlikowska, J., et al. (2006) Reconstructing the early evolution of Fungi using a six-gene phylogeny. Nature, $443,818-822$.

Kentaro Yoshida, Verena J Schuenemann, Liliana M Cano, Marina Pais, Bagdevi Mishra, Rahul Sharma, Chirsta Lanz, Frank N Martin, Sophien Kamoun, Johannes Krause, Marco Thines, Detlef Weigel, \& Burbano, H.A. (2013) The rise and fall of the Phytophthora infestans lineage that triggered the Irish potato famine. eLife, 2, e00731.

King, J.E. (1977) Surveys of diseases of winter wheat in England and Wales 1970-75. Plant Pathology, $26,8-20$.

Lovell, D.J., Hunter, T., Powers, S.J., Parker, S.R., \& van den Bosch, F. (2004) Effect of temperature on latent period of septoria leaf blotch on winter wheat under outdoor conditions. Plant Pathology, 53, $170-181$.

Madden, L., Hughes, G., \& van den Bosch, F. (2007) The Study of Plant Disease Epidemics APS Press, St. Paul, Minnesota

Meentemeyer, R.K., Rank, N.E., Shoemaker, D.A., Oneal, C.B., Wickland, A.C., Frangioso, K.M., \& Rizzo, D.M. (2008) Impact of sudden oak death on tree mortality in the Big Sur ecoregion of California. Biological Invasions, 10, 1243-1255.

Mougou, A., Dutech, C., \& Desprez-Loustau, M.-L. (2008) New insights into the identity and origin of the causal agent of oak powdery mildew in Europe. Forest Pathology, 38, 275-287.

Newcombe, G. \& Dugan, F.M. (2010). Fungal Pathogens of Plants in the Homogocene. (In Y. Gherbawy \& K. Voigt(eds), Molecular Identification of Fungi). Berlin: Springer.) 
Packer, A. \& Clay, K. (2004) Development of negative feedback during successive growth cycles of black cherry. Proceedings of the Royal Society B, 271, 317-324.

Paveley, N., Blake, J., Gladders, P., Cockerell, V., Oxley, S., Gosling, P., \& Nicholls, C. (2013) HGCA Wheat disease management guide Agriculture and Horticulture Development Board, , Stoneleigh Park, Warwickshire, UK.

Peters, J.C. (1994) Pattern and impact of disease in natural plant communities of different age. PhD thesis, Reading.

Peters, J.C. \& Shaw, M.W. (1996) Effect of artificial exclusion and augmentation of fungal plant pathogens on a regenerating grassland. New Phytologist, 134, 295-307.

Preston, C.D., Pearman, D.A., \& Dines, T.D. (2002) New Atlas of the British and Irish Flora Oxford University Press, Oxford.

Roy, B.A., Coulson, T., Blaser, W., Policha, T., Stewart, J.L., Blaisdell, G.K., \& Gusewell, S. (2011) Population regulation by enemies of the grass Brachypodium sylvaticum: demography in native and invaded ranges. Ecology, 92, 665-675.

Scherm, H., Ngugi, H.K., \& Ojiambo, P.S. (2006) Trends in theoretical plant epidemiology. European Journal of Plant Pathology, 115, 61-73.

Shaw, M.W. (1994) Seasonally induced chaotic dynamics and their implications in models of plant disease. Plant Pathology, 43, 790-801.

Shaw, M.W. (2011) “....two blighted ears of Wheat, which few persons would have thought it worth while to carry with them round the world...". . The Microbiologist, 12, 36-39.

Shaw, M.W. (2013). Chaotic dynamics of pathosystems. (In K.L. Stevenson \& M.J. Jeger(eds), Exercises in Plant Disease Epidemiology 2nd ed). St. Paul, Minnesota: APS Press.) 
Shaw, M.W., Bearchell, S.J., Fitt, B.D.L., \& Fraaije, B.A. (2008) Long-term relationships between environment and abundance in wheat of Phaeosphaeria nodorum and Mycosphaerella graminicola New Phytologist, 177, 229-238.

Shaw, M.W. \& Peters, J.C. (1994). The biological environment and pathogen population dynamics: uncertainty, coexistence and competition. (In P. Blakeman \& B. Williamson(eds), The Ecology of Plant Pathogens, (pp. 17-37). Wallingford, UK: CABI.)

Stukenbrock, E.H. \& McDonald, B.A. (2008) The origins of plant pathogens in agro-ecosystems. Annual Review of Phytopathology, 46, 75-100.

Tomley, A.J. \& Evans, H.C. (2004) Establishment of, and preliminary impact studies on, the rust, Maravalia cryptostegiae, of the invasive alien weed, Cryptostegia grandiflora in Queensland, Australia Plant Pathology, 53, 475-484.

van den Berg, F. \& van den Bosch, F. (2004) A model for the evolution of pathogen-induced leaf shedding. Oikos, 107, 36-49.

van den Berg, F., van den Bosch, F., Powers, S.J., \& Shaw, M.W. (2008) Apical leaf necrosis as a defence mechanism against pathogen attack: effects of high nutrient availability on onset and rate of necrosis. Plant Pathology, 57, 1009-1016.

Walters, D.R., Havis, N.D., \& Oxley, S.J.P. (2008) Ramularia collo-cygni: the biology of an emerging pathogen of barley. FEMS Microbiology Letters, 279, 1-7.

Weir, A.H., Bragg, P.L., Porter, J.R., \& Rayner, J.H. (1984) A winter wheat crop simulation model without water or nutrient limitations. Journal of Agricultural Science, Cambridge, 102, 371-382. 
Xiaoqiang, L., Jie, Z., Ji, S., Chengyu, W., Hongli, Z., \& Qianli, S. (2004) Vegetation history and climatic variations during the last 14 ka BP inferred from a pollen record at Daihai Lake, north-central China. Review of Paleobotany and Palynology, 132, 195-205.

Zadoks, J.C. (1987) The function of plant pathogenic fungi in natural communities. Geobotany, 10, 201-207.

Zaffarano, P.L., McDonald, B.A., \& Linde, C.C. (2008) Rapid speciation following recent host shifts in the plant pathogenic fungus Rhynchosporium. Evolution, 62, 1418-1436. 


\section{Figure Legends}

Fig. 1 Incidence of disease on a range of scales in space and time. (Top row) At any scale, we can ask for incidence at sub-units within that scale; patterns may vary or be self-similar as here (Bottom row) At any spatial scale, we can ask questions about how pathogen incidence changes over time on a range of scales. Time-scales could vary from the geological (in which case our question might be about a taxonomic unit larger than a species) to sub-annual, which is the conventional agricultural scale.

Fig. 2 Silene otites incidence in grids placed in occupied squares of successively finer-grained grids, from Jalas \& Suominen (1986) and Preston et al. (2002). S. otites has no natural scale; whatever size unit is chosen about 1 in 4 grid squares will be occupied, up to a limit which is the complete species range.

Fig. 3 Output of a completely deterministic model of the interaction of a host, pathogen and hyperparasite, showing sporadic short or long outbreaks punctuated by periods of up to a century of consistently low severity. Within the growing season, pathogen increases according to a logistic with susceptibility decreasing during the season. The hyperparasite multiplies logistically on the pathogen, in proportion to its own and pathogen density. Between growing seasons, both pathogen and hyperparasite are greatly reduced, representing the decay of host tissue. Equations are given in Shaw (in press); pathogen infection rate $=0.1025 \mathrm{day}^{-1}$; hyperparasite infection rate $=0.12$ day $^{-1}$; $10 \%$ of each population survives the winter.

Fig. 4 Holocene temperature record from central Asia (Xiaoqiang et al., 2004), showing the very substantial changes in conditions and vegetation assemblages over the last 10000 years, since the end of the last glaciation (say a few hundred generations of a large forest tree).

Fig. 5 A typical historical report of disease severity, displaying political bias, vagueness over terms, and unquantifiability (Anon, 1890). We can reasonably say from this that blight severity in 1890 was 
worse than in 1889 , and that it cannot have been so bad that people gave up planting in 1891 . This is unfortunately rather imprecise for compiling a detailed severity record, but typical of the available sources. 